\title{
Mass transport properties of mature wasteform grouts
}

\author{
H.S. Wong ${ }^{1 \mathrm{a}}$, N.R. Buenfeld ${ }^{\mathrm{a}}$, J. Hill ${ }^{\mathrm{b}}$ and A.W. Harris ${ }^{\mathrm{b}}$ \\ ${ }^{a}$ Concrete Durability Group, Imperial College London, SW7 2AZ, UK \\ ${ }^{b}$ U.K. Nirex Ltd., Harwell, Oxfordshire, OX11 ORH, UK.
}

\begin{abstract}
Release of gases from intermediate level radioactive wastes encapsulated in cement-based wasteform grouts is a major concern during the interim storage, transportation and operational stage of a phased geological repository system. The ability of the wasteform grout to retain radioactive gases depends on its mass transport properties, which evolve with age, water saturation degree and any degradation. This paper reports the gas diffusion, gas permeation and water absorption (sorptivity) coefficients of two mature wasteform grouts containing 75\% pulverised fuel ash or $75 \%$ blast furnace slag. Some of the slag grouts were found to be affected by microcracking, and these were subsequently examined using backscattered electron microscopy and quantified using a specifically developed image analysis procedure. Prior to transport testing, samples were conditioned in a realistic manner to a range of water saturation levels (10-100\%). The mass transport properties were found to be highly dependent on the degree of water saturation, in particular for samples conditioned at relative humidity greater than $55 \%$. The microcracks have a significant effect on permeability, but less influence on diffusion and water absorption. Implications of the results on the effectiveness of these grouts for radioactive waste containment are presented.
\end{abstract}

Keywords: Concrete technology \& manufacture; Concrete structures; Waste management \& disposal

\section{Introduction}

Encapsulation and immobilisation in cement-based materials is the favoured method in the UK for the passivation of intermediate level radioactive waste (ILW) ${ }^{1}$. Composite cements based on the replacement of OPC with

\footnotetext{
${ }^{1}$ Corresponding author: Tel: +44 (0)20 7594 5957; Fax: +44 (0)20 72252716

E-mail address: hong.wong@imperial.ac.uk
} 
either pulverised fuel ash (PFA) or blast furnace slag (BFS) are commonly used as they offer several advantages over Portland cement, notably a lower heat of hydration. This is needed to avoid a high thermal gradient which may cause cracking, hence compromising the effectiveness of encapsulation. Use of PFA or BFS also improves the overall microstructure, strength and transport properties of the composite, reduces cement consumption and provides a means of disposing of by-products from the metallurgical industry and coal-burning power stations.

In support of Government policy, Nirex is responsible for developing safe, environmentally sound and publicly acceptable options for the long-term management of radioactive materials in the United Kingdom. ${ }^{2}$. One of the aims of Nirex is to develop coherent concepts which include a range of practical and viable options for the longterm management of radioactive materials, including the Phased Geological Repository Concept (PGRC) for $\mathrm{ILW}^{3}$. Typically, the wastes are immobilised in a cement-based grout, i.e. the 'wasteform', then enclosed in stainless steel or concrete containers. The 'waste package' is then transported to a monitored and retrievable storage system in deep (300-1000m) underground repositories excavated in stable rock formations, where it is less vulnerable to disruption by man-made or natural events. After a period of monitoring, the repository may be backfilled, sealed and finally closed. Hence, the PGRC uses both engineered and natural barriers to create a multi-barrier containment system to prevent or to reduce the release of radio-toxic substances to a safe level, while the natural process of radioactive decay occurs.

A number of wastes have the potential to generate significant quantities of gases such as $\mathrm{H}_{2}, \mathrm{CO}_{2}, \mathrm{CH}_{4}, \mathrm{~N}_{2}, \mathrm{H}_{2} \mathrm{~S}$ and $\mathrm{O}_{2}$ from corrosion of metals, microbial degradation of organic materials and radiolysis of water. The accumulation and pressure build-up of these gases may have an adverse effect on the long-term integrity of the waste package and repository ${ }^{4,5}$. The possibility of damage from over-pressurisation can be reduced by specifying limits on gas generation rates in waste packages, ensuring sufficient permeability of the wasteform and proper venting ${ }^{6}$. Radioactive gases, such as radon from the decay of radium, on the other hand, are produced in much smaller quantities, but present a more immediate concern due to radio-toxicity. The retention of radon or the control of its release rate, may be an important factor in designing and endorsing the methods used in the packaging of waste and in assessing its potential safety impact to workers and the public during interim surface storage ( $\sim 150$ years), transport, handing, emplacement and the operational period ( $\sim 50$ years) of the repository. Consequently, Nirex has provided guidance to producers of radioactive wastes on the packaging of wastes that may generate significant quantities of radon ${ }^{6,7}$.

As part of the continuing development and refinement of Nirex guidance, the migration of radon through cementitious grouts has been modelled to provide a basis for demonstrating the expected performance of packaged 
wastes $^{8}$. The relatively short half-lives of all radon isotopes ( $<4$ days) means that the delay introduced by migration through the tortuous microstructure of an intact cementitious wasteform, and the consequent decay of the radon, offers important benefits in minimising safety impacts due to waste packages where immobilisation in cement is the preferred packaging method. The validity of any conclusions based on such modelling is sensitive to the assumed properties of the cementitious materials, and in particular the gas migration properties.

Wasteform grouts may dry out due to hydration, self-desiccation and evaporation during storage, causing an increase in gas migration properties. Thus, the effect of pore water saturation and its evolution must be considered. However, it is apparent that the majority of published data on transport properties of cement-based materials are mainly for dry or fully saturated conditions, while results for partially saturated material (dried in a realistic manner) have not been widely reported probably due to experimental difficulties. There are some studies on gas migration in model cement pastes, mortars and concretes under partially saturated conditions ${ }^{9-13}$ and some data on cementitious materials specifically used in repositories as structural members and for backfilling ${ }^{14-17}$. Nevertheless, very limited data exists for mature, high cement replacement grouts commonly used in the packaging of radioactive wastes.

The present study aims to investigate the transport properties of two mature, 5-year old grouts used for ILW encapsulation that contain large amounts of PFA and BFS. In order to replicate the actual disposal environment, both grouts were conditioned for 6 months to a range of relative humidities and degrees of water saturation so that the effects of sample drying on the transport properties could be characterised. Oxygen diffusivity, oxygen permeability and water sorptivity were measured. Some samples from the BFS grout were found to be affected by various degrees of microcracking; the microcracks were imaged using optical and scanning electron microscopy techniques and an image analysis technique was developed to segment the cracks and quantify the degree of cracking, in order to ascertain their effect on mass transport properties.

\section{Experimental}

\subsection{Sample preparation and curing}

Two grouts were investigated in this study: a) Mix S with 3:1 BFS: OPC ratio at w/b $=0.35$; and b) Mix P with 3:1 PFA: OPC ratio at $w / b=0.42$. These represent two of the common grouts used in the packaging of radioactive wastes. For the BFS/OPC grout, w/b in the range $0.33-0.37$ has been widely investigated and slight variations have been used in actual plants so the 0.35 value is in the mid-range ${ }^{18}$. For the PFA/OPC grout, the 0.42 
w/b ratio is often used as a 'capping grout' to cover/seal the top of an existing wasteform ${ }^{19}$. This study is to investigate the performance of typical formulations for packaging wastes, rather than the influence of w/b. These $\mathrm{w} / \mathrm{b}$ values are used as a compromise between low water to give low diffusivity and to limit corrosion of wastes when immobilised, and high water to give fluidity for infiltration of wastes (superplasticisers are currently not used due to concerns regarding the possible complexation of some radionuclides species such as plutonium).

The grouts were mixed in 1998 using a 60 litre Hobart planetary mixer. De-ionised and nitrogen-sparged water was used to minimise carbonation. Mixing was conducted within a loose polythene tent purged with argon. Four cylindrical samples (100mm diameter, 200mm length) were cast from each grout mixture. Samples were vibrated until no air bubbles were observed emanating from the surface. The moulded samples were then sealed in loose wrapping and cured for 2 days at $20 \pm 2^{\circ} \mathrm{C}$ and at relative humidity $>90 \%$. Subsequently, they were demoulded, sealed in polythene wrapping and stored in sealed plastic containers containing soda lime 'Carbosorb'. In 2003, the $\sim 5$ year-old cylinders were sent to Imperial College London for testing.

\subsection{Sample conditioning}

The cylinders were sectioned using an abrasive cutter fitted with a diamond blade. Approximately $10 \mathrm{~mm}$ of material from the bottom (cast) face and 40mm material from the top (trowelled) face of each cylinder were discarded and the remaining portion was sectioned to produce seven $20 \mathrm{~mm}$ thick discs. The discs were designated with S or P, representing either BFS or PFA grout, followed by a number (1-4) representing each cylinder and a second number (1-7) representing the location of the disc from the bottom cast face. For the BFS grout, all cylinders except one (S3) were found to be affected by cracking. Since the cylinders were sectioned every $20 \mathrm{~mm}$ from the bottom, we were able to study the nature of the cracks and how they changed with position.

From the total of 28 discs prepared for each mix, 25 discs were used for mass transport testing and 3 discs were used for microscopy. For transport testing, a set of 5 discs selected from different cylinders to span their entire length, were conditioned at $21^{\circ} \mathrm{C}$ and a relative humidity ( $\mathrm{RH}$ ) of $0 \%, 35 \%, 55 \%, 75 \%$ or $86 \%$. The discs for microscopy were conditioned at RH $0 \%, 55 \%$ and $86 \%$. The conditioning humidity was achieved using silica gel and appropriate saturated salt solutions. The conditioning boxes were kept free of $\mathrm{CO}_{2}$ using soda lime, the $\mathrm{RH}$ was constantly monitored and the silica gel/salt solutions were replaced when necessary. The discs were conditioned for 22 weeks, after which, they were sealed in cling-film for another week to allow for moisture redistri- 
bution within the discs prior to testing. The rate of mass loss at the end of the conditioning regime was less than $0.02 \%$ per day in all cases.

\subsection{Transport testing}

The discs were tested following the sequence of oxygen diffusion, oxygen permeation and water absorption. In this sequence, the same sample can be used throughout since successive test results are not affected by the previous test. All tests were conducted at $21^{\circ} \mathrm{C}$.

\subsubsection{Oxygen diffusion}

Oxygen diffusivity was measured in an oxygen-nitrogen binary mixture ${ }^{20}$. The disc was fitted into a silicon rubber ring in a diffusion cell and sealed by axially loading the rubber ring, which expands laterally, providing an air-tight grip onto the sample. Blank tests on a steel disc of similar dimensions showed no measurable flow across the disc, confirming that the seal is effective. The test was carried out by exposing one flat face of the disc to a stream of pure oxygen and the opposite face to a stream of pure nitrogen at approximately the same pressure. The absolute pressure on the inlet face was no more than 1.004 bars and the pressure difference between inlet and outlet face was no more than 0.0015 bars. The oxygen and nitrogen counter diffuse through the sample and the oxygen concentration at the outlet face was monitored constantly using a zirconia analyser (measurable range from $0.25 \mathrm{ppm}$ to $25 \%$ ) until steady-state condition. The effective average intrinsic oxygen diffusion coefficient, $\mathrm{D}\left(\mathrm{m}^{2} / \mathrm{s}\right)$, was then determined using Fick's first law of diffusion:

$$
D=\frac{Q \times L}{A \times\left(C_{2}-C_{1}\right)}
$$

Where Q $\left(\mathrm{m}^{3} / \mathrm{s}\right)$ is oxygen diffusion rate, $\mathrm{L}(\mathrm{m})$ and $\mathrm{A}\left(\mathrm{m}^{2}\right)$ are the sample thickness and cross-sectional area respectively, $\mathrm{C}_{1}$ and $\mathrm{C}_{2}$ are the oxygen concentrations in the outflow and inflow streams respectively. A comprehensive mathematical description of the inter-diffusion of two gases is beyond the scope of this paper, but is available elsewhere ${ }^{20}$. 


\subsubsection{Oxygen permeation}

The test involved applying an oxygen pressure gradient across the sample and measuring the steady-state flow rates using a series of bubble flow meters. The permeability cell to house the sample was identical to that used in the diffusion test. Three input pressures of 0.5, 1.5 and 2.5 bars above atmospheric pressure was used, hence the pressure gradient applied across the disc was between 2.5 and $12.5 \mathrm{MPa} / \mathrm{m}$. A test on a steel disc of similar dimensions at the highest operating pressure found no leakage through the sides. Five readings were taken to compute the average flow for each applied pressure. The oxygen permeability coefficient, $k_{g}\left(\mathrm{~m}^{2}\right)$, was calculated from Darcy's equation for compressible fluid flow:

$$
Q=\frac{k_{g} A}{2 \eta L}\left(\frac{P_{1}^{2}-P_{2}^{2}}{P_{2}}\right)
$$

Where $\mathrm{Q}$ is the outflow rate $\left(\mathrm{m}^{3} / \mathrm{s}\right), \eta$ is the oxygen viscosity at $20^{\circ} \mathrm{C}\left(=2.02 \times 10^{-5} \mathrm{Ns} / \mathrm{m}^{2}\right), \mathrm{P}_{1}$ and $\mathrm{P}_{2}$ are the absolute pressures on inlet and outlet faces respectively $\left(\mathrm{N} / \mathrm{m}^{2}\right)$. The calculated permeability coefficient from Eq. 2 decreases with applied pressure due to gas slippage, so this was corrected by using the Klinkenberg method ${ }^{21}$ :

$$
k_{g}=k_{\mathrm{int}}\left[1-\frac{\beta}{P_{m}}\right]
$$

Where $k_{\text {int }}\left(m^{2}\right)$ is the intrinsic permeability, $P_{m}$ (bar) is the mean pressure $\left(=1 / 2\left(P_{1}+P_{2}\right)\right)$ and $\beta$ is the Klinkenberg constant. The intrinsic permeability was obtained from the $\mathrm{y}$-intercept of the best-fit line of the $\mathrm{k}_{\mathrm{g}}$ versus 1/P $\mathrm{P}_{\mathrm{m}}$ plot. All except for seven discs from the BFS grout: S1-6 (RH: 55\%), S1-7, S2-1, S4-3 (RH: 75\%), S1-1, S2-2 and S4-7 (RH: 86\%), showed a strong linear correlation between $\mathrm{k}_{\mathrm{g}}$ and $1 / \mathrm{P}_{\mathrm{m}}\left(\mathrm{R}^{2}>0.9\right)$. These seven discs did not display the Klinkenberg effect probably because most of the capillary pores were saturated at high RH and thus, flow occurred predominantly through large cracks via a viscous mechanism in contrast to Knudsen flow. For these samples, an alternative approach was used to calculate the permeability coefficient. The outflow rate, $\mathrm{Q}$, was plotted against $\left(\mathrm{P}_{1}{ }^{2}-\mathrm{P}_{2}{ }^{2}\right) / \mathrm{P}_{2}$ for all three input pressures and the best-fit line $\left(\mathrm{R}^{2}>0.99\right)$ was determined. The apparent permeability coefficient, $k_{a p p}\left(\mathrm{~m}^{2}\right)$, was calculated from the slope of the best-fit line, viscosity and sample dimensions as per Eq. 2. This method implicitly assumes that the permeability coefficient is independent of the applied pressure.

Fig. 1 compares the intrinsic permeability (Eq. 3) to the apparent permeability (Eq. 2) for all samples. Generally, a good agreement is observed between these coefficients. As expected, the intrinsic permeability is smaller than 
the apparent permeability for all samples. However, the apparent permeability for the BFS grout is on average, only $12 \%$ larger than the intrinsic permeability. Note that the input pressure during permeability testing is insufficient to cause expulsion of pore water from the partially saturated samples. In fact, the measured mass difference before and after testing for permeability as well as diffusion, rarely exceeded $0.05 \%$ for the wettest samples, indicating that significant drying did not occur during testing. Hence, the gaseous transport in these tests can be treated as a single phase flow process.

\subsubsection{Water absorption}

Water absorption testing involved monitoring the mass gain of a sample in contact with water with time until saturation was achieved. The sample was placed on two plastic rods in shallow deionised water ( $\sim 2$ to $3 \mathrm{~mm}$ above inflow face) to allow free water access. The sample mass was measured at: 5, 10, 20, 30, 60 minutes, then at hourly intervals for the next 6 hours and then daily until the sample reached saturation. Prior to weighing, surface water was removed with dampened tissue. Each weighing was completed within 30s and the clock was allowed to run during the weighing operation. The tray was covered with a loose fitting lid to avoid drying of the samples. This creates a humid, but not saturated environment. The RH in the container was about $50-70 \%$ and approached $80-90 \%$ when the sample was near saturation.

The mass of absorbed water per unit inflow area was plotted against the square-root of time. The sorptivity coefficient $\left(\mathrm{g} / \mathrm{m}^{2} \cdot \mathrm{min}^{0.5}\right)$ was determined from the slope of the best-fit line drawn across the first ten readings $\left(\mathrm{R}^{2}>\right.$ 0.99). Results from the PFA grout showed a typical bi-linear plot where an initial rapid rise in mass is followed by a cross-over to a slower rate of mass gain (Fig. 2). However, for the BFS grouts conditioned at low humidity $(<55 \%)$, the results showed a sigmoidal, instead of a bi-linear trend (Fig. 2). The initial mass gain is followed by a more rapid mass gain, before achieving saturation. The first ten readings from which the sorptivity coefficient was determined lie prior to the inflection point. The time at which the inflection point occurred, coincided very well with the appearance of triple-branch map-cracking patterns on the top surface of the affected discs. The cause and implications of this anomalous behaviour will be discussed in the Results section.

\subsection{Porosity, degree of water saturation and non-evaporable water content}

Immediately after the water absorption test, the discs were brought to full saturation by immersion in deionised water for 48 hours, and then dried at $105^{\circ} \mathrm{C}$ until constant mass. The porosity and degree of water saturation 
were calculated from the sample mass measured at the end of the conditioning regime, at saturated-surface dry and at oven-dry conditions. Subsequently, the discs were crushed and a small sample $(\sim 50 \mathrm{~g})$ was placed in a crucible and heated to $1050^{\circ} \mathrm{C}$. The amount of weight lost between $105^{\circ} \mathrm{C}$ and $1050^{\circ} \mathrm{C}$ was used to compute the non-evaporable water content.

\subsection{Sample preparation for microscopy}

Epoxy impregnated, flat-polished samples were prepared for electron microscopy. After conditioning, block samples (40 x $20 \times 10 \mathrm{~mm}$ ) were sectioned from each disc at approximately mid-distance from the centre to the edge. The samples were freeze-dried, epoxy impregnated under vacuum, then ground using silicon carbide papers of successively finer grit size of 220, 500, 1000 and 1200. Finally, the blocks were polished using diamond at 9, 6, 3, 1 and $1 / 4 \mu \mathrm{m}$. The polishing time for each stage was kept short ( 5 minutes) to reduce surface relief. A non-aqueous solution was used as lubricant for cutting and polishing. Acetone was used as cleaning fluid. The polished samples were carbon coated and imaged in the backscattered electron mode using a JEOL 5410LV scanning electron microscope.

\subsubsection{Procedure for crack analysis}

An example of BFS grout with a characteristic circular crack pattern is shown in Fig. 3(a). The cracks were clearly visible in the BFS grout because of partial oxidation of sulphide, judged by the colour change from dark greenish blue of the complex polysulphide products to creamy coloured sulphate. The cracks allow ingress of air and hence, promote the oxidation of paste areas surrounding them. The resulting colour conversion gives a high contrast between areas in the vicinity of cracks and areas further away. Since the amount of oxidisation is linked to the extent of cracking, we can indirectly quantify the degree of cracking by measuring the area fraction of the creamy-coloured paste using image analysis.

The surface of each BFS disc was scanned using a commercial flat-bed scanner at 266dpi, producing a 24bit colour 1100 x 1100 pixels image at approximately $0.1 \mathrm{~mm}$ pixel spacing. The surface quality of the sectioned disc was sufficient to give a good starting image without the need of additional grinding/polishing. Before any measurements can be made, the colour image must be reduced to a binary image whereby the feature of interest, in this case the oxidised area, is segmented from other areas. This is performed by selecting appropriate thresholds that define the range of brightness values corresponding to the feature of interest. 
Obviously, the accuracy of the measurement depends critically on the segmentation process. For colour images, segmentation can be done by defining thresholds on either one or a combination of the three available colour bands. For this study, we found that thresholding on the hue component of the HSI colour space gave a well segmented image. The hue component of the original image was first extracted to produce a greyscale image (Fig. 3(b)) in which the cracked areas are highly contrasted. The brightness histogram of this greyscale image, plotted in Fig. 3(c), shows well-defined bimodal peaks representing the oxidised and other areas. Thus, a threshold level can be set at the mid-point between peaks to separate the two features, giving a binary image shown in Fig. 3(d). The degree of cracking is then expressed as the percentage of the oxidised area to the sample crosssection area; this value is termed the 'crack index'. It is emphasised that this method does not directly measure the total crack volume fraction, but provides an indication of the extent of cracking.

\section{Results}

\subsection{Degree of water saturation, porosity and non-evaporable water content}

Fig. 4 plots the change in degree of water saturation with conditioning at different relative humidities. Note that both grouts were able to maintain a near $100 \%$ saturated state during the 5 years curing in a high RH environment. When exposed to $\mathrm{RH}<90 \%$, both grouts began to dry out, with the PFA grout drying at a higher rate than the BFS grout. By the end of the 22-week conditioning period, the degree of water saturation ranged between 10 to $100 \%$ for all samples. The BFS grout recorded a significantly higher degree of saturation compared to the PFA grout. A larger difference was observed at lower conditioning humidity; decreasing from $64 \%$ at $0 \% \mathrm{RH}$ to $16 \%$ at $86 \% \mathrm{RH}$.

Table 1 gives the average porosity values (5 replicates) for each cylinder and for each mix type, calculated by expressing the mass difference between the saturated-surface dry and oven-dry condition $\left(105^{\circ} \mathrm{C}\right)$ as a percentage of the bulk sample volume. Note that this value includes the capillary pores, cracks and air voids as well as gel pores. The values in parentheses represent the coefficients of variation of the average porosity values. The results show that samples made from the same grout have approximately the same porosity, hence are representative of that particular mix. As expected, the higher w/b ratio PFA grout contained a slightly higher porosity compared to the BFS grout.

It is interesting to note that whilst the BFS grout has a lower porosity than the PFA grout, the degree of water saturation can be more than twice that of the PFA grout conditioned at the same humidity. Even at $0 \%$ RH, more 
than $40 \%$ of the pore space in the BFS grout is still occupied by moisture compared to about $15 \%$ for the PFA grout. The cracks present in the BFS grout did not appear to greatly facilitate drying of the sample. This indicates that the BFS grout has a much finer and more tortuous pore structure such that for a given relative humidity, most of the pores remain in a saturated condition. This is consistent with the phenomenon of condensation in fine capillaries as predicted by the Kelvin-Laplace equation. The remaining pore water is held strongly by surface adsorption and can only be removed by drying at elevated temperature.

The non-evaporable water content was found to be virtually independent of the conditioning humidity. The average non-evaporable water content for the PFA grout and BFS grout was $11.3 \%$ and $10.5 \%$ respectively, with a coefficient of variation of less than $2 \%$ for both cases. Therefore, the differences in the measured transport properties of samples conditioned at various humidity levels cannot be attributed to further hydration caused by conditioning.

\subsection{Mass transport properties}

The effect of degree of water saturation on the diffusivity, permeability and water sorptivity of the BFS and PFA grout is illustrated in Fig. 5. Each data point corresponds to one sample. The results show that the transport coefficients are highly dependent on the degree of water saturation. This is well-known and is consistent with the fact that gas migration and water absorption only occur through empty pores and cracks. Thus, conditioning at lower humidity increases the available transport paths, resulting in higher transport rates.

It is interesting to note that a significant drop in transport properties occurred between RH 55\% and RH 86\%, but drying below 55\% RH caused a negligible increase in transport coefficients. This implies that most of the capillary pores and cracks relevant to transport are emptied when the sample is in equilibrium to $55 \% \mathrm{RH}$, which is consistent with the work by Powers \& Brownyard ${ }^{22}$ on water vapour absorption isotherms of cement pastes, which showed that capillary pores only begin to condensate at RH greater than about $45 \%$. Although further drying removes more pore water, the additional empty fine capillaries and gel pores are too small to make a significant contribution to transport.

For both grouts, depending on the degree of water saturation, the oxygen diffusivity and permeability ranged from $3.9 \times 10^{-10}$ to $4.5 \times 10^{-8} \mathrm{~m}^{2} / \mathrm{s}$ and from $6.2 \times 10^{-20}$ to $1.2 \times 10^{-16} \mathrm{~m}^{2}$ respectively. The sorptivity was between 1.8 and $260 \mathrm{~g} / \mathrm{m}^{2} \cdot \mathrm{min}^{0.5}$. The BFS grouts consistently recorded lower diffusivity and sorptivity, but gave unexpectedly higher permeability compared to PFA grouts that were conditioned at the same humidity (despite the fact 
that the BFS grouts have a higher degree of saturation). This shows that the cracks observed in the BFS grout samples had a more significant effect on permeation than on diffusion or water absorption.

The transport coefficients for samples from cylinder S3 were always lower than those for other BFS grout samples that were conditioned at the same humidity. In the most severe case, which was for permeability, the difference between a 'cracked' and 'non-cracked' sample was as high as 1.5 orders of magnitude. This again shows that the cracks observed on S1, S2 and S4, had a deleterious effect on mass transport, in particular pressureinduced flow.

\subsection{Characteristics of cracks in the BFS grout}

Fig. 3A and Fig 6 show some images of different crack morphologies, taken immediately after the cylinders were sectioned (prior to conditioning). On the plane surface, at least four types of crack pattern were observed and these distinctive patterns appeared at about the same relative positions on the cylinders. Discs nearest to the bottom cast face showed a band of co-centric circular cracks with radius of approximately half that of the cylinder (Fig. 3A). Discs located near the top trowelled face also displayed circular cracks, but these were formed closer to the edge. Discs taken from the mid-position of the cylinders displayed radial cracks that appear to originate from the edge propagating towards the centre (Fig. 6A). Other cracks appear to have random orientation (Fig. 6B). On the cross-section, a different form of crack morphology was observed (Fig. 6C). Some cracks appeared to run vertically through the thickness of the disc, while others were aligned in the horizontal plane. The density of the horizontal cracks was as high as 1.25 per mm and they appear to be interconnected to the edge of the sample. These horizontal cracks may cause anisotropy in the transport properties of the grout, but unfortunately, this was not measured in the present study.

Backscattered electron (BSE) imaging found that the cracks had widths of up to $100 \mu \mathrm{m}$. Fig. 7 is a BSE image of a typical crack showing rough edges with angular slag particles and occasionally hydration products bridging the gap between both sides of the paste. This suggests that the cracks were formed early in the life of the samples and that subsequent hydration caused partial healing. The cracks are likely to be due to tensile stresses from restrained deformation; the restraint probably came from the steel mould in which the grout was cast. This was compounded by the high autogenous shrinkage in slag cements and the high self-desiccation tendency in a low w/b ratio mix. 
Cracks form orthogonal to the direction of the maximum principal tensile stress. Thus, when the grout is restrained from shrinkage by the external cylindrical mould, the principle tensile stress is in the radial direction, causing a circular co-centric crack pattern to develop on the discs. For the bottom discs, a wide band of circular cracks was formed because the entire cross-section was restrained by the base plate of the mould. Discs located higher up show circular cracks near the edge since the restraint is only coming from the side wall of the mould. At mid-position, the crack orientation and direction of the principal tensile stress appears to have interchanged for unknown reasons, causing cracks to develop radially.

BSE imaging did not find similar crack patterns in the PFA grout. As a comparison, Fig. 8 shows a BSE image of a typical microstructure of a PFA grout taken at the same magnification. It is observed that the PFA grout contains many fly ash cenospheres of about $1-300 \mu \mathrm{m}$ in diameter. Most of the cement particles have hydrated leaving behind traces of bright ferrite phases.

Fig. 9 shows another form of cracking found on samples from the BFS grout that were conditioned at very low humidity $(<55 \%)$. Note that these triple-branch cracks appeared during the water absorption test (coinciding with the inflection point on the water absorption plot in Fig. 2) and are different from the cracks shown previously in terms of morphology and distribution. They occurred on all samples conditioned at $0 \% \mathrm{RH}$, even for those from S3 (Fig. 9A). BSE imaging found that that these are very fine cracks with widths less than $1 \mu \mathrm{m}$ (Fig. 9B). It is likely that these are drying shrinkage cracks induced by the severe conditioning regime.

\subsection{Image analysis}

Fig. 10 shows 3-D surface plots illustrating the combined effect of cracking and degree of water saturation on the transport coefficients. We stress again that the crack index is not a measure of crack volume fraction, but an indicator of the extent of cracking. The crack index inevitably overestimates the actual crack volume fraction because of the way in which it is measured. No effort was made to correct for this. It may be argued that this index is erroneous due to inclusion of paste areas at the edges that have been oxidised by direct air exposure via capillary pores and not via cracks, but closer inspection using optical and electron microscopy did find cracking in these areas. Furthermore, examination of discs from S3 (Fig. 9A) found only a negligible amount of oxidation occurring near the edges. Nevertheless, interpretations of Fig. 10 should only be qualitative because the amount of data is insufficient to generate a surface plot that is statistically significant. 
The measured crack index using image analysis ranged from $2 \%$ to $30 \%$. As expected, the surface plots show that samples with a high degree of saturation and a low crack index will have lower transport properties. Cracking can increase transport coefficients by up to two orders of magnitude for samples at approximately the same saturation degree. The cracks appear to have a more significant effect when the sample is near $100 \%$ saturation and for the case of pressure-induced flow. This shows that at high humidity conditions, the capillary pores are blocked due to condensation, but the larger cracks remain empty, providing easy access for mass transport. The effect of cracking on transport properties is less evident when the sample is dry because the capillary pores are now empty and can also contribute to mass transport.

\section{Discussion}

It may be instructive to compare the results of this study with others, but bearing in mind the differences in mix formulations, age, curing/conditioning regimes and testing methods. In general, we found that the transport coefficients for the wasteform grouts in this study were in the range of values typically reported for cement-based materials ${ }^{9-18}$. For example, Lawrence ${ }^{20}$ reported that the $\mathrm{O}_{2}$ diffusivity in a $\mathrm{N}_{2}-\mathrm{O}_{2}$ binary mixture for a 28-day cured, w/c 0.36 OPC concrete conditioned to $55 \%$ RH was $2 \times 10^{-9} \mathrm{~m}^{2} / \mathrm{s}$. Using a similar set up, Kobayashi \& Shuttoh ${ }^{9}$ found that the $\mathrm{O}_{2}$ diffusivity for various 28-day water cured, w/c 0.6 concretes with 30-70\% BFS conditioned to $60 \%$ water content to be in a range of $1-2 \times 10^{-8} \mathrm{~m}^{2} / \mathrm{s}$. Houst \& Wittmann ${ }^{10}$ measured the $\mathrm{CO}_{2}$ and $\mathrm{O}_{2}$ diffusivity on carbonated cement pastes (w/c 0.4), cured for 6 months in saturated lime water and conditioned to $50-90 \%$ RH. The values ranged from $3 \times 10^{-9}$ to $1 \times 10^{-8} \mathrm{~m}^{2} / \mathrm{s}$.

For gas permeability, Harris et al. ${ }^{16}$ studied the migration of He and Ar in a 9:1 BFS:OPC grout at w/c 0.4, used for encapsulation of solid and liquid ILW. The average intrinsic gas permeability was $5 \times 10^{-16} \mathrm{~m}^{2}$ and $6 \times 10^{-18} \mathrm{~m}^{2}$ for oven dried samples $\left(100^{\circ} \mathrm{C}\right)$ and for samples conditioned to $100 \% \mathrm{RH}$ respectively. In another study, Galle \& Daian $^{17}$ measured the $\mathrm{N}_{2}$ permeability of cement pastes prepared using CEM 1 (100\% OPC) and CEM V (55\% OPC, 22\% BFS, 23\% PFA) at w/b 0.3 to 0.5 , used in the French nuclear waste industry. Samples were cured in saturated limewater for 9 months then conditioned to 10-100\% water saturation. The effective gas permeability measured at 1-2 MPa was found to be between $10^{-21}$ and $10^{-16} \mathrm{~m}^{2}$. For water absorption, Hall ${ }^{23}$ reported a sorptivity value of about $90 \mathrm{~g} / \mathrm{m}^{2} \mathrm{~min}^{0.5}$ for w/c 0.4 OPC concretes that were oven dried at $40^{\circ} \mathrm{C}$. Unpublished results from the first author of this paper found sorptivity values of about $200 \mathrm{~g} / \mathrm{m}^{2} \mathrm{~min}^{0.5}$ for 28 -day cured OPC pastes with $30 \% \mathrm{FA}$ and $60 \% \mathrm{BFS}$ at w/c 0.3 . These samples were conditioned to $55 \% \mathrm{RH}$ prior to testing. 
This study shows that the wasteform grouts can maintain a near $100 \%$ water saturation state for a long period of time in a high humidity environment. The diffusivity and sorptivity for samples conditioned at $86 \%$ RH is about $10^{2}$ smaller than the values for samples conditioned at $0 \%$ RH. For permeability, a difference of $10^{3}$ is observed. This shows that it may be beneficial to consistently maintain the storage/repository at a high humidity condition in order to provide a better retention of radioactive gases. However, the advantages derived from a lower mass transport property of a highly saturated wasteform grout may need to be balanced against the possibility of increased production of other bulk gases, either from a higher corrosion rate or microbial degradation, which can affect the integrity of the container due to over-pressurisation. The mass transport properties of the wasteform grout can be engineered to ensure that the potential for the release of radionuclide is as low as possible, but sufficiently permeable to disperse bulk gases.

The release of radon from waste packages would be controlled by a diffusion mechanism through the encapsulating material. Pressurisation due to radon is not likely to be a concern since the volume of radon generated from wastes would be small ${ }^{7}$. Unfortunately, there are no data available on radon diffusivity of cementitious grout commonly used in radioactive waste containment. Since radon is 7 times heavier and is slightly more soluble in water than oxygen, the diffusivity of radon in wasteform grouts under similar conditions is expected to be smaller than the values obtained in this study. As a crude estimation, considering that the free diffusivities of radon and oxygen in air are $1.1 \times 10^{-5} \mathrm{~m}^{2} / \mathrm{s}$ and $2.0 \times 10^{-5} \mathrm{~m}^{2} / \mathrm{s}$ respectively, the radon diffusivity in the wasteform grouts would be at least a factor of two lower than the values for oxygen diffusivity obtained in this study, i.e. in the range $2 \times 10^{-10}$ to $2 \times 10^{-8} \mathrm{~m}^{2} / \mathrm{s}$. This range of values appears to be somewhat smaller than the range of values reported for concrete ${ }^{24-28}$, that is $7.5 \times 10^{-9}$ to $4 \times 10^{-7} \mathrm{~m}^{2} / \mathrm{s}$. Note that the present Nirex guidelines for packaging radon generating wastes ${ }^{7}$ do not specify limits for the mass transport properties of the wasteform grout. Simple control of radon release can be achieved by limiting the radium-226 content in waste packages. Where a justified allowance is made for radon retention and decay within the wasteform grout, such conservative limits for radium-226 content may be relaxed.

Although the BFS grout was affected by microcracking, it consistently recorded lower diffusivity and sorptivity, higher saturation degree and substantially higher permeability than a similarly conditioned PFA grout. This shows that the microcracks have a more significant effect on pressure-induced flow, but lesser effect on diffusivity or water absorption. The microcracks have high connectivity and low tortuosity compared to capillary pores such that when the sample is under a pressure gradient, flow will predominantly occur via the microcracks since they offer transport paths having the least amount of resistance. This is supported by the observation that several 
of the cracked BFS grout samples did not display the Klinkenberg effect during permeability testing. Diffusion and water absorption, on the other hand, occur more 'evenly' through the microstructure because one is a process of random atomic collisions while the other is due to capillary effects.

The sigmoidal trend in the water absorption plots (Fig. 2) for the BFS grout was totally unexpected. To the best of our knowledge, this anomalous behaviour has not been reported before. We hypothesise that the first linear portion of the curve is mainly due to water absorption into the sub-micron triple-branch cracks and capillary pores, since they offer the strongest capillary suction. When these sub-micron cracks begin to saturate, they become visible on the top surface of the disc (Fig. 9A), hence the time at which they appear coincided very well with the inflection point on the curve. Subsequent absorption occurs mainly into the larger cracks (Fig. 7) and contributes to the second mass increase in the absorption plot.

The observed microcracking in the BFS grout may only be a characteristic of the samples investigated and it is not known whether a similar crack pattern would emerge when it is used for actual waste encapsulation. Typical wastes can be in a variety of physical forms and sizes. Addition of solid wastes may increase the resistance to crack formation by improving toughness, ductility and by reducing shrinkage. Hence, in this aspect, the amount of microcracking observed in the BFS grout may represent a worst-case scenario in practice.

\section{Summary}

This study investigated the influence of degree of water saturation and microcracking on the mass transport properties of two mature grouts containing $75 \%$ slag (w/b 0.35) and pulverised fuel ash (w/b 0.42) that were designed for immobilisation of low-level radioactive wastes. The grouts were cured in a high humidity environment for five years and were then conditioned to a range of water saturation degree (10-100\%). For both grouts, depending on the degree of water saturation, the oxygen diffusivity and permeability ranged from $3.9 \times 10^{-10}$ to $4.5 \times 10^{-8} \mathrm{~m}^{2} / \mathrm{s}$ and from $6.2 \times 10^{-20}$ to $1.2 \times 10^{-16} \mathrm{~m}^{2}$ respectively. The sorptivity was between 1.8 and 260 $\mathrm{g} / \mathrm{m}^{2} \cdot \mathrm{min}^{0.5}$. The transport coefficients were significantly reduced at higher water saturation due to the reduction in the volume of available pores for transport, in particular when samples were conditioned to a relative humidity greater than $55 \%$. The diffusivity and sorptivity for samples conditioned at $86 \%$ RH was about $10^{2}$ smaller than the values for samples conditioned at $0 \%$ RH. For permeability, a difference of $10^{3}$ was observed. Substantial microcracking (widths $\sim 10-100 \mu \mathrm{m}$ ) was found in the BFS grout. The microcracks were due to shrinkage of the grout during its early curing in steel moulds. The characteristics of these cracks were examined using backscat- 
tered electron microscopy and quantified using a specifically developed image analysis procedure. The cracks were found to have a marginal effect on gaseous diffusion and water absorption, but a significant effect on permeability. This shows that pressure-induced flow occurs preferentially through the microcracks, which offer transport paths of least resistance due to their high connectivity and low tortuosity.

\section{Acknowledgements}

This project was funded by Nirex Ltd. HSW would like to acknowledge the financial support provided by the Universities UK, via the Overseas Research Students Awards Scheme. We thank Mr. R.A. Baxter for his help with the laboratory work.

\section{References}

[1] CROSSLAND I.G., The role of engineered barriers in a UK repository for intermediate level radioactive waste, Interdisciplinary Science Reviews (UK), 1998, 23, 3, 269-280.

[2] UK Nirex Limited, Options for Radioactive Waste Management that have been Considered by Nirex, Nirex Report N/049, 2002, 39p.

[3] UK Nirex Limited, The Viability of a phased geological repository concept for the long-term management of the UK's radioactive waste, Nirex Report N/122, 2005,

[4] RODWELL W.R., HARRIS A.W., LALIEUX P., HORSEMAN S.T., MÜLLER W., ORTIZ AMAYA L. and PRUESS K., Gas migration and two-phase flow through engineered and geological barriers for a deep repository for radioactive waste, A Joint EC/NEA Status Report published by the European Commission, 1999, European Commission Report EUR 19122 EN.

[5] RODWELL W.R., HAIJTINK B. and LALIEUX P., The impact of gas on the safety of underground waste repositories, NEA Newsletter, 1999, 17, 2, 18-20.

[6] UK Nirex Limited, Generic Waste Package Specification, Nirex Report N/104, 2005.

[7] UK Nirex Limited, Waste Package Specification and Guidance Documentation: Guidance Note on the Packaging of Radon-generating Wastes, Nirex Report WPS/902, 2005, 35p. 
[8] RODWELL W.R., SWIFT B.T., Estimation of the release of radon from 500 litre drums of groutencapsulated intermediate-level nuclear waste, SERCO/ERRA-0374, 2, 2003.

[9] KOBAYASHI K., SHUTTOH K., Oxygen diffusivity of various cementitious materials, Cem. Concr. Res., 1991, 21, 273-284.

[10] HOUST Y. F., WITTMANN F.H., Influence of porosity and water content on the diffusivity of $\mathrm{CO}_{2}$ and $\mathrm{O}_{2}$ through hydrated cement paste, Cem. Concr. Res., 1994, 24, 6, 1165-1176.

[11] PARROTT L.J., Moisture conditioning and transport properties of concrete test specimens, Mater. Struct., 1994, 27, 460-8.

[12] JACOBS F., Permeability to gas of partially saturated concrete, Mag. Concr. Res., 1998, 50, 115-121.

[13] ABBAS A., CARCASSES M., OLLIVIER J.-P., Gas permeability of concrete in relation to its degree of saturation, Materials and Structures, 1999, 32, 3-8.

[14] PIHLAJAVAARA S.E., Long-term gas permeability properties of concrete in wet repository conditions, Nuclear Engineering and Design, 1991, 129, 41-48.

[15] IRIYA K., JACOBS F., KNECHT B., WITTMANN F.H., Cementitious backfill materials for a L/ILW repository - Investigations of gas transport properties, Nuclear Engineering and Design, 1991, 129, 4955.

[16] HARRIS A.W., ATKINSON A., CLAISSE P.A., Transport of gases in concrete barriers, Waste Management, 1992, 12, 155-178.

[17] GALLE C., DAIAN J.-F., Gas permeability of unsaturated cement-based materials: application of a multi-scale network model, Mag. Concr. Res., 2000, 52, 4, 251-263.

[18] FAIRHALL G.A., PALMER J.D., The Encapsulation of Magnox Swarf in Cement in the United Kingdom, Cem. Concr. Res., 1992, 22, 293-298.

[19] CONStABle M., FENTON A., JONES D.V.C., LEE D.J., WILDING C.R., Elevated Temperature Grouts and Radioactive Waste Inventory, DoE Report DoE/RW/90.063, 1990.

[20] LAWRENCE C.D., Transport of oxygen through concrete, The Chemistry and Chemically-Related Properties of Cement, British Ceramic Society Proceedings, 1984, 35, 277-293. 


\section{Tables}

\begin{tabular}{|c|c|c|c|c|c|c|c|c|}
\hline Cylinder & $\mathrm{P} 1$ & $\mathrm{P} 2$ & P3 & $\mathrm{P} 4$ & $\mathrm{~S} 1$ & $\mathrm{~S} 2$ & S3 & S4 \\
\hline Porosity (\%) & $\begin{array}{l}45.1 \\
(2.9)\end{array}$ & $\begin{array}{l}43.7 \\
(4.7)\end{array}$ & $\begin{array}{l}44.1 \\
(2.1)\end{array}$ & $\begin{array}{l}45.0 \\
(1.4)\end{array}$ & $\begin{array}{l}38.4 \\
(0.9)\end{array}$ & $\begin{array}{l}38.1 \\
(3.2)\end{array}$ & $\begin{array}{l}38.0 \\
(2.8)\end{array}$ & $\begin{array}{l}37.7 \\
(3.3)\end{array}$ \\
\hline Average (\%) & \multicolumn{4}{|c|}{44.5 (3.1) } & \multicolumn{4}{|c|}{$38.1(2.6)$} \\
\hline
\end{tabular}

[21] KLINKENBERG L.J., The permeability of porous media to liquids and gas, Drilling and Production Practice, 1941, American Petroleum Institute, 200-213.

[22] POWERS T.C., BROWNYARD T.L., Studies of the physical properties of hardened Portland cement paste, Bulletin 22, Research Laboratories of the Portland Cement Association, Skokie, IL, reprinted from J. Am. Concr. Inst., 1947, 43, 101-132, 249-336, 469-505, 549-602, 669-712, 845-880, 933-992.

[23] HALL C., Water sorptivity of mortars and concretes: a review, Mag. Concr. Res., 1989, 41, 51-61.

[24] CULOT M.V.J., OLSON H.G., SCHIAGER K.J., Effective diffusion coefficient of radon in concrete: Theory and method for field measurement, Health Physics, 1976, 30, 263-270.

[25] ZAPALAC G.H., Time-dependent method for characterizing Rn-222 in concrete, Health Physics, 1983, 45, 377-383.

[26] HOLUB R.F., DROULLARD R.F., BORAK T.B., INKRET W.C., MORSE J.G., BAXTER J.F., Radon222 and 222Rn progeny concentrations measured in an energy-efficient house equipped with a heat exchanger, Health Physics, 1985, 49, 267-277.

[27] POFFIJN A., BERKVENS P., VANMARCKE H., BOURGOIGNIE R., On the exhalation and diffusion characteristics of concrete, Radiation Protection Dosimetry, 1988, 24, 203-206.

[28] SNODDY R., Laboratory assessment of the permeability and diffusion characteristics of Florida concretes: Phase II, Field samples and analyses, Environmental Protection Agency Report, EPA-600/R95/103, 1995.

\section{variation.}




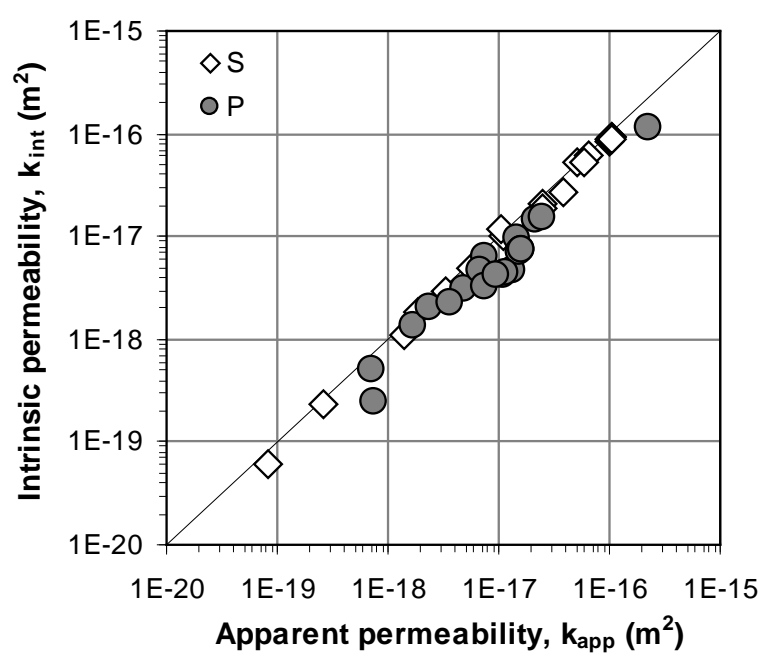

Figure 1 Intrinsic permeability (Eq. 3) plotted against apparent permeability (Eq. 2) for BFS (S) and PFA (P) grouts.

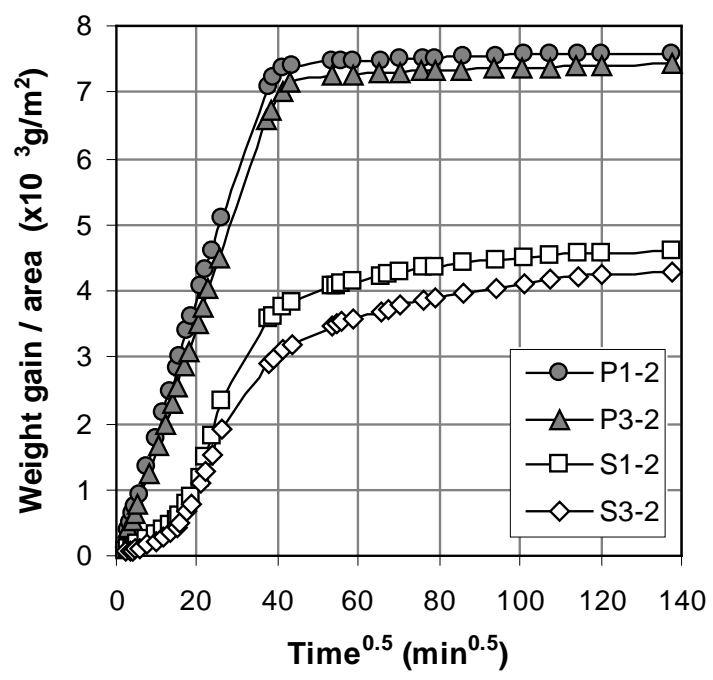

Figure 2 Water absorption plots for PFA (P) and BFS (S) grouts conditioned at $0 \%$ RH. Results from the BFS grouts displayed a sigmoidal behaviour instead of a typical bi-linear curve as shown by the PFA grouts. 

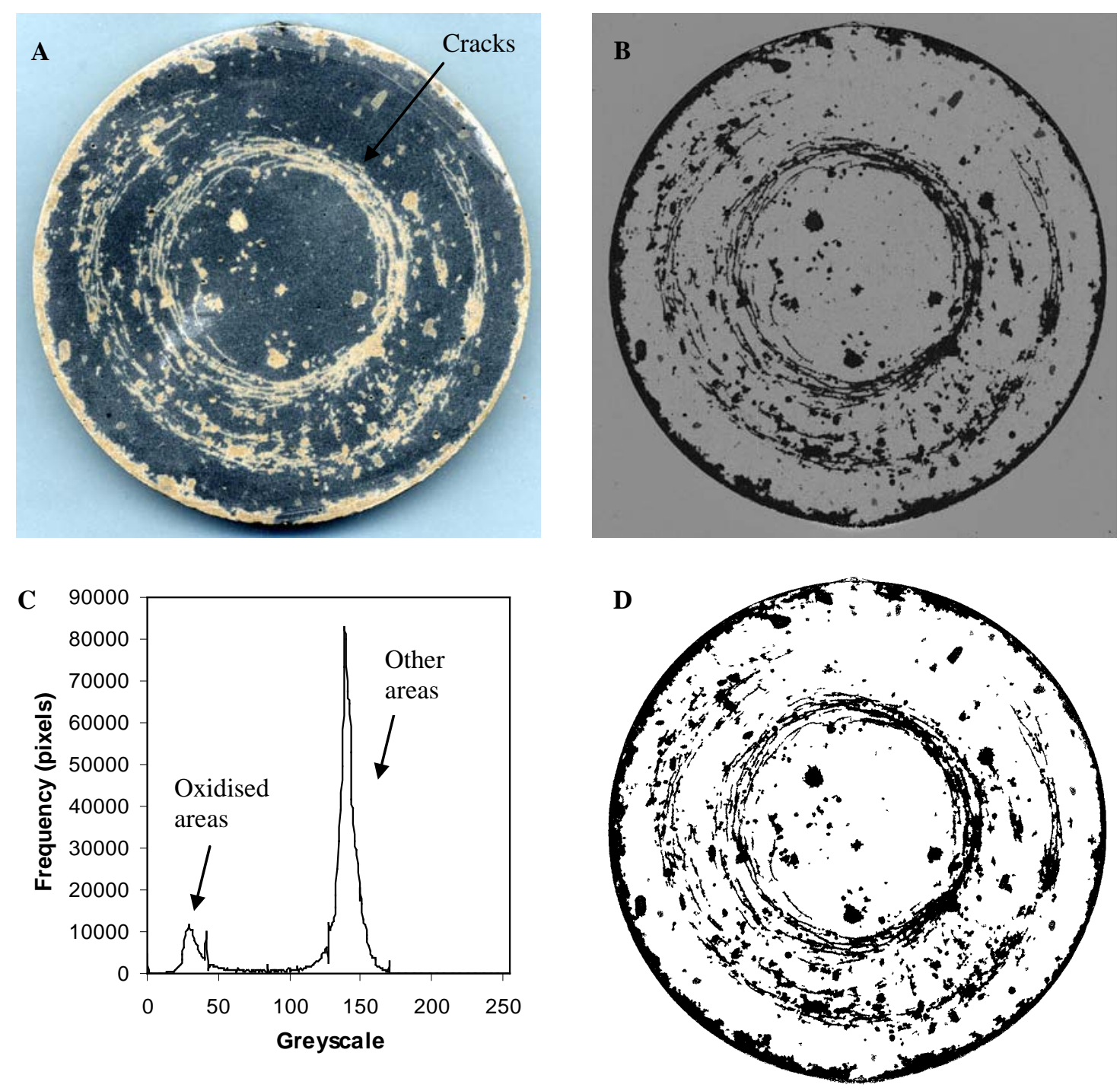

Figure 3 Algorithm for crack segmentation: A) scanned image of sample S1-1; B) extracted hue component; C) brightness histogram of B showing separate peaks representing oxidised and other areas; and D) binary image of the segmented oxidised area. Crack index $=21.6 \%$. 

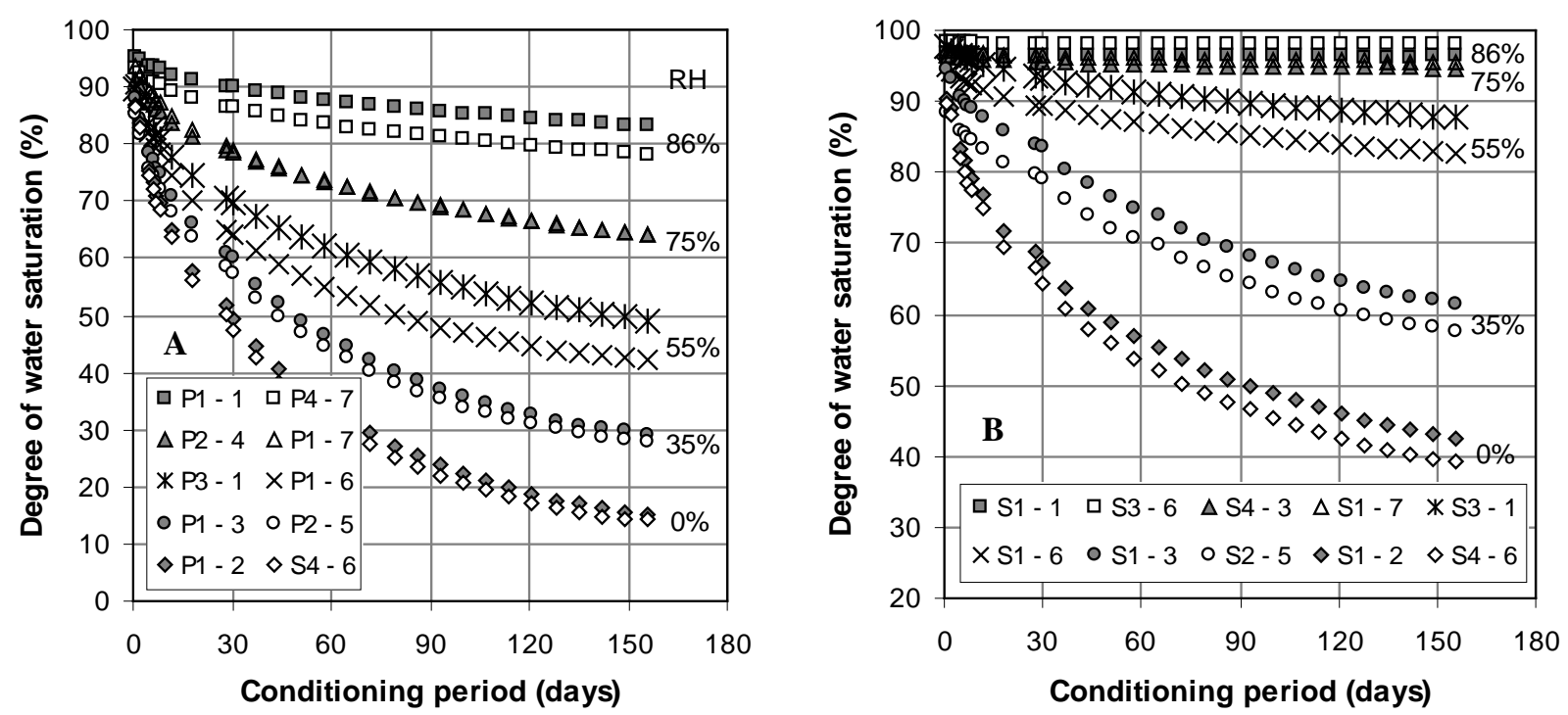

Figure 4 Change in degree of water saturation with conditioning period and relative humidity for PFA
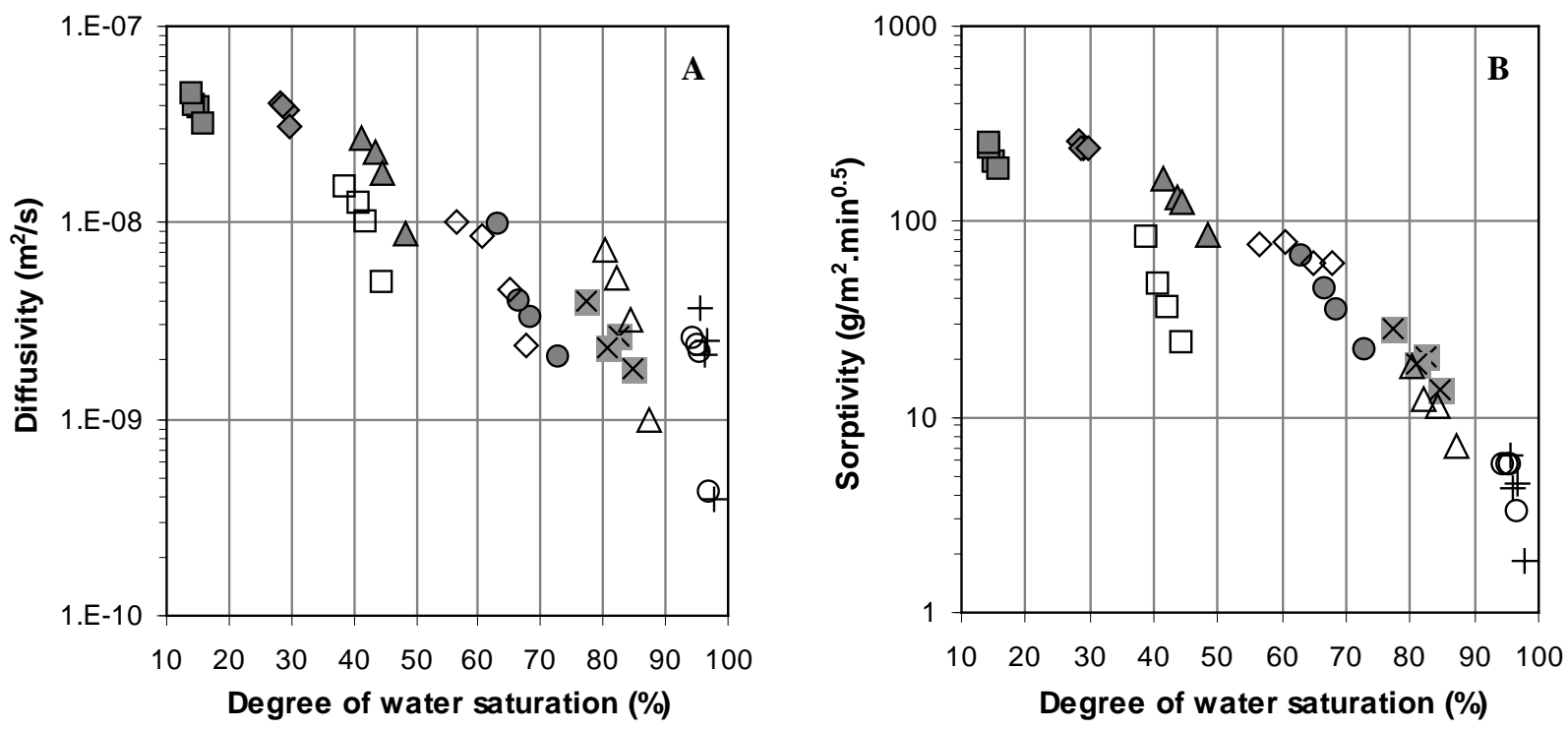


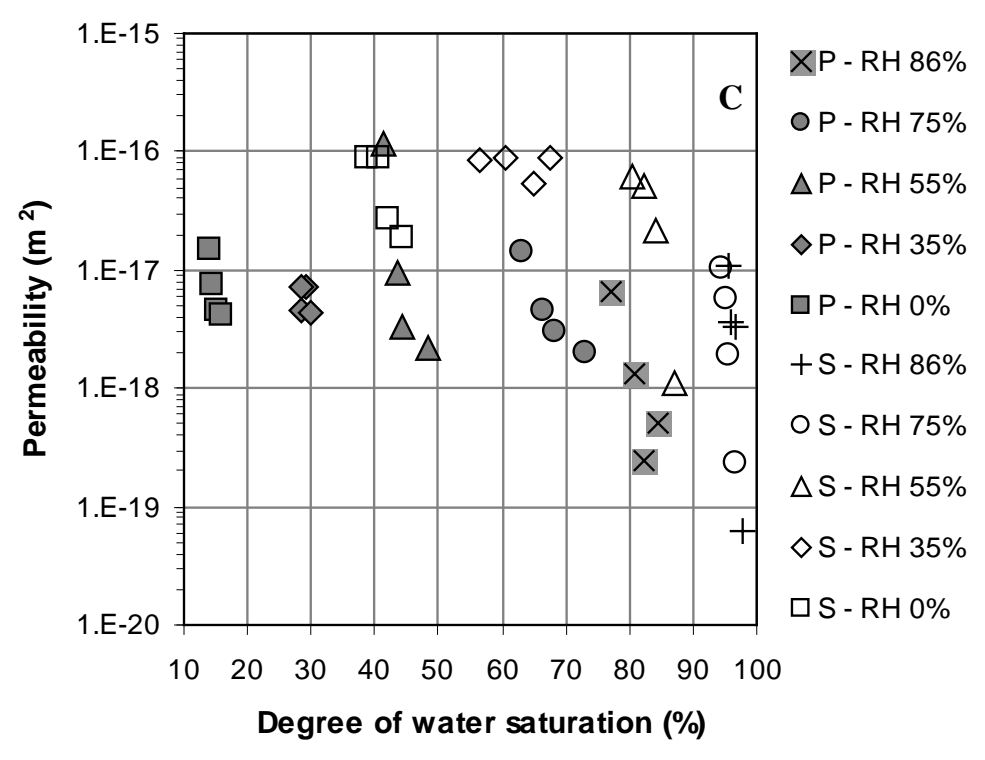

511 Figure 5 Effect of degree of water saturation on oxygen diffusivity (A), water sorptivity (B) and oxygen 512 permeability (C).
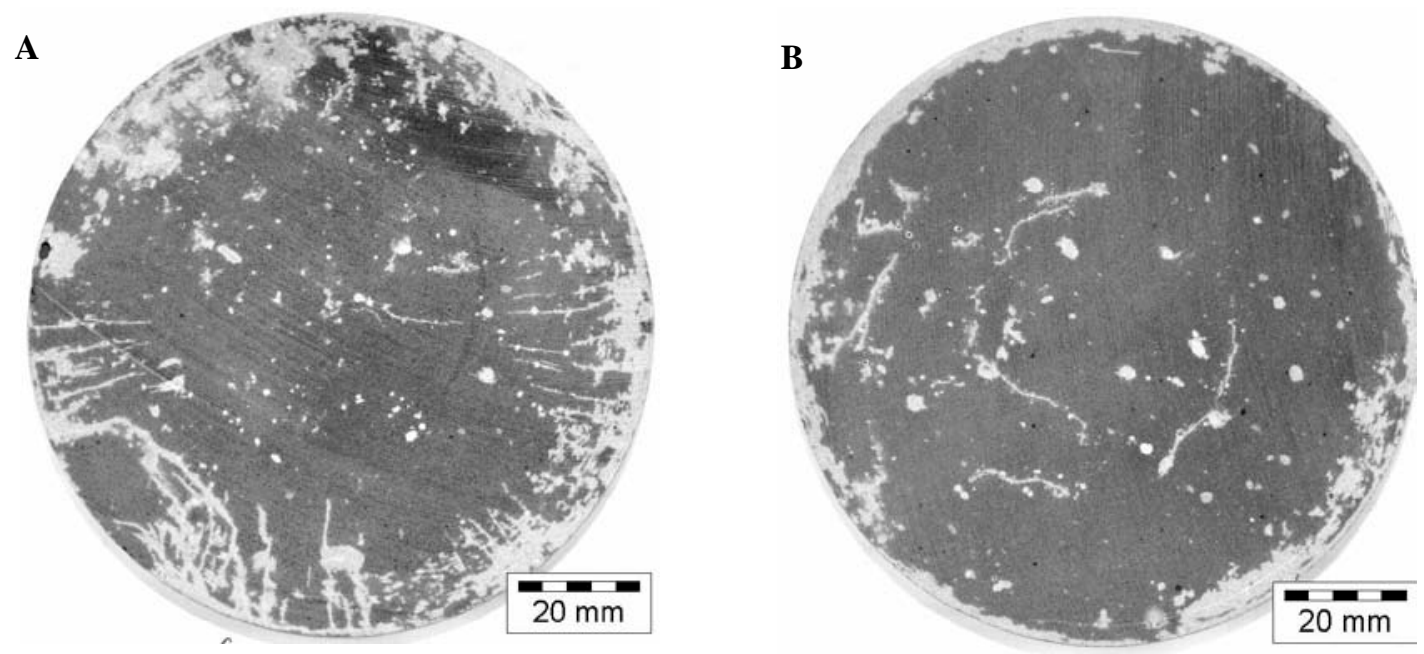

C
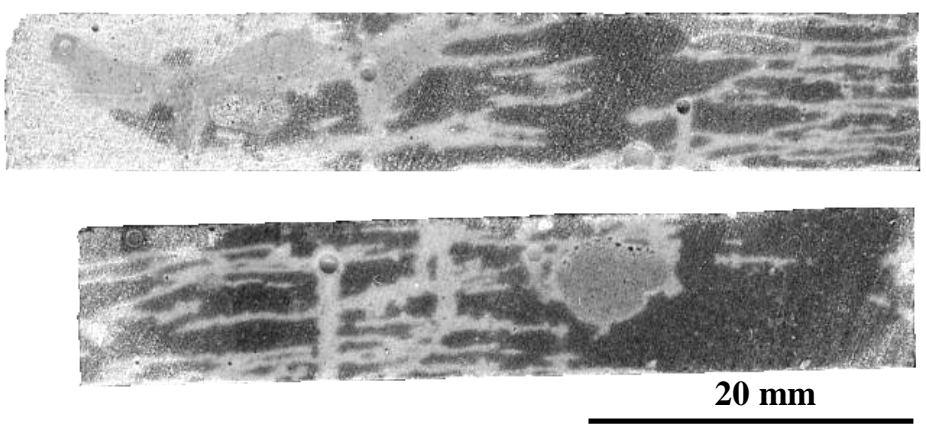

Figure 6 Various crack morphologies observed on the plane surface (A, B) and on the cross-section (C) of discs from the BFS grout. 


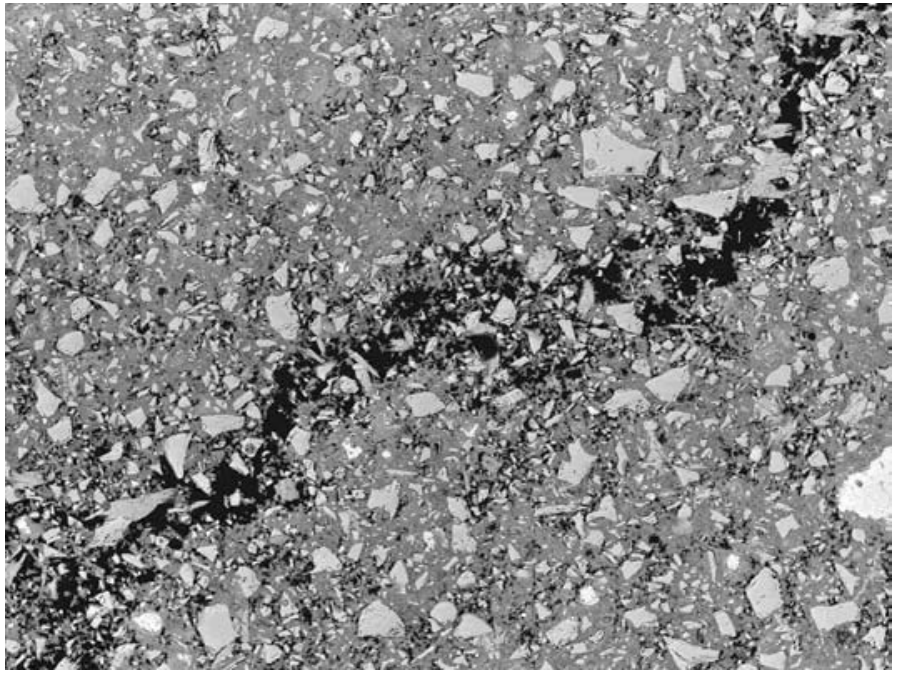

Figure 7 BSE image of a typical crack found in the BFS grout samples. The crack has rough edges with mately 35 to $65 \mu \mathrm{m}$. Image was taken at $100 \mathrm{x}$; field of view is $1200 \times 900 \mu \mathrm{m}$.

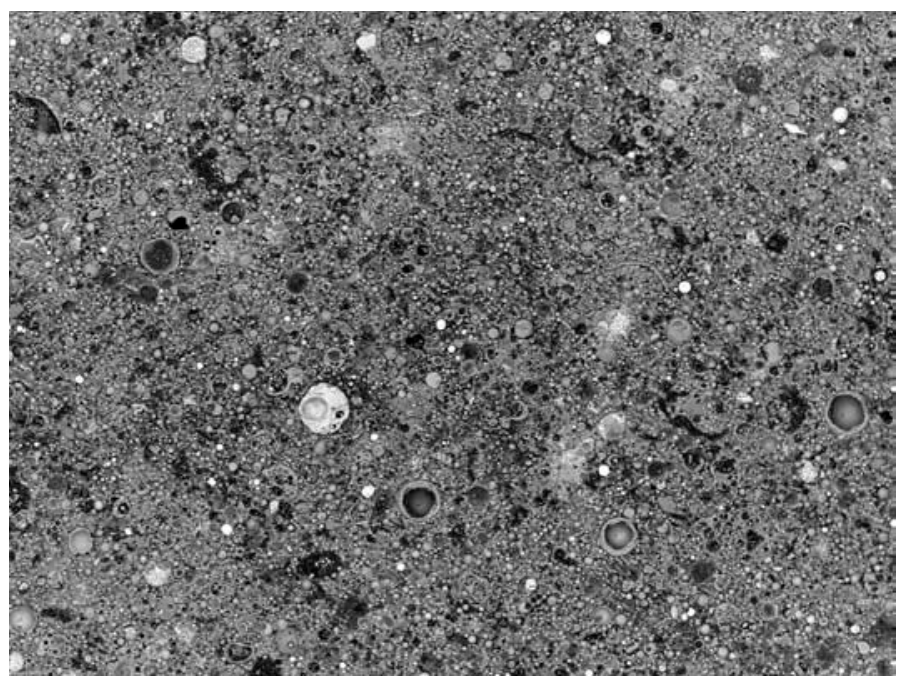
$100 x$; field of view is $1200 \times 900 \mu \mathrm{m}$. 

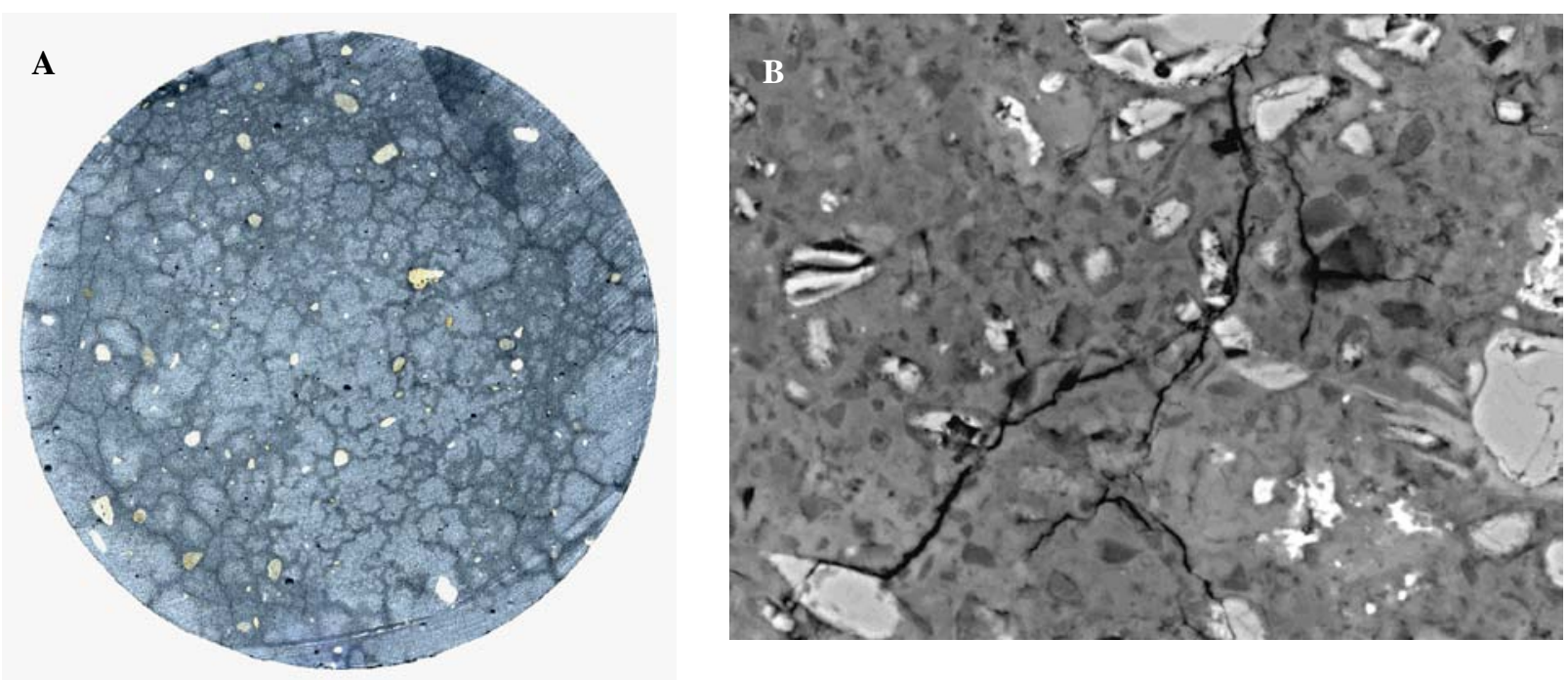

Figure 9 A) Triple-branch cracks observed during water absorption testing. These are due to drying shrinkage from conditioning at very low humidity $(<55 \%)$; B) BSE imaging found that these triplebranch cracks are sub-micron in width. Imaged at $1000 \mathrm{x}$; field of view is $120 \times 90 \mu \mathrm{m}$.
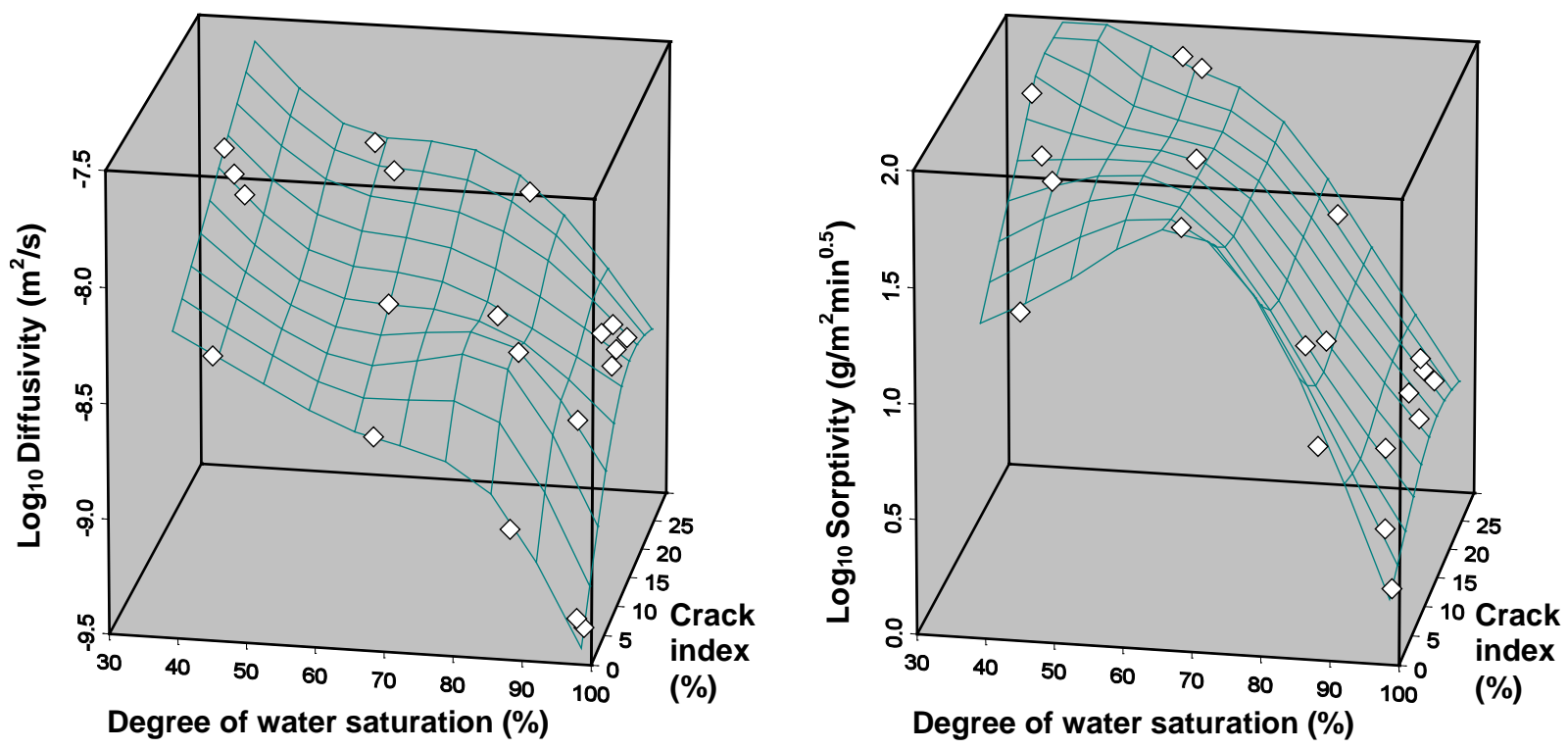


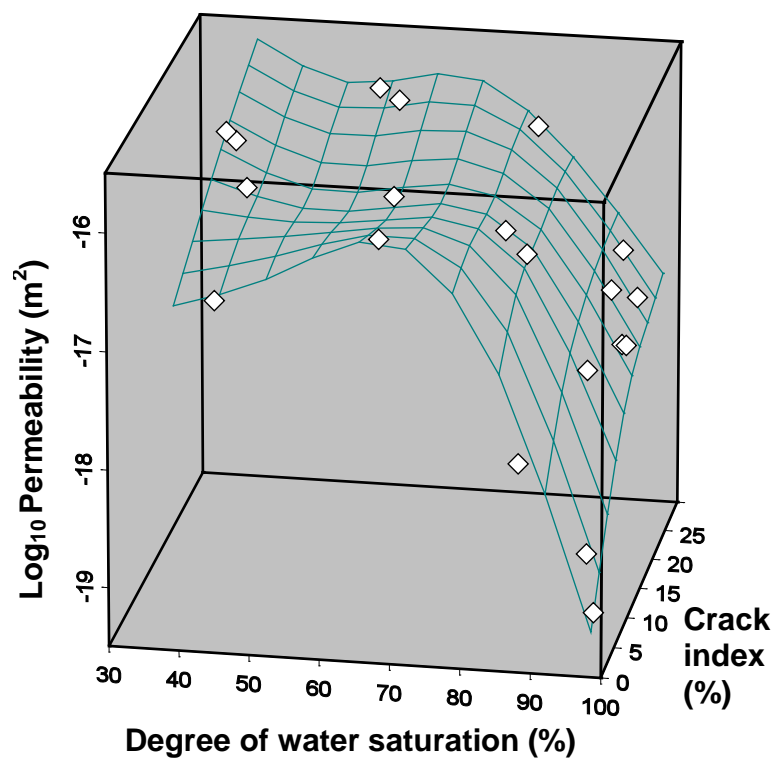

